diverticulae was thought unlikely to cause folate deficiency but may have contributed to the B12 deficiency. The coeliac disease (case 2) had been present for several years, was stable, and had not previously caused macrocytosis. The poor diet (case 3) was long standing and had not previously caused macrocytosis. A mild haemolysis does occur with sulphasalazine treatment (case 4).

We would emphasise that treatment with sulphasalazine has an experimentally proved mechanism for inducing folate deficiency, which is dose dependent. The paper by Grindulis and McConkey cited by Dr Greaves and coworkers concluded that "caution is therefore necessary if more than 2 grams of sulphasalazine daily is given in rheumatoid arthritis; in such circumstances clinical or haematological evidence of deficiency is more likely to develop because the mechanism by which the drug antagonises folate metabolism is dose dependent." All but one of our patients received a higher dose than this.

Peter Prouse DEIDRE SHAWE

J M GUMPEL

Northwick Park Hospital,

Middlesex HA1 3UJ

1 Grindulis KA, McConkey B. Does sulphasalazine cause folate deficiency in rheumatoid arthritis? Scan $\mathcal{f}$ Rheumatol 1985;14:265-70.

\section{Social future of elderly admitted to acute care hospital}

SIR,-In the study by Dr Françoise RoudotThoraval and colleagues ( 7 March, p 608) 32 of the 39 patients discharged to long term care had a negative view of it at the start of their acute admission, and no patient who was free of family pressure wanted to be transferred to long term care. The factor that predicted whether a patient would go into long term care was the view of the family, not that of the patient.

Secondly, though it is difficult to find a comparable British series, a transfer rate from acute to long term care of $31 \%$ seems very high. Might this high transfer rate itself be responsible for the strong correlation between being transferred to a long term bed and staying longer in the acute one? Perhaps the local long stay sector is unable to cope with this transfer rate and the system is dealing with the overload by allowing a backup of patients in the acute sector.

I have not seen the cited papers by Kane et al but presume that they report American experience. As to the importance of the age and mental state of the patient, several British studies have shown them to be valuable in predicting the outcome of hospital admissions. ${ }^{1-3}$

In this unit we emphasise the need for very early involvement of the family in an old person's care. In the difficult balance between taking risks and preserving independence, however, we believe that British families tend to opt for safety at the expense of freedom. We would therefore advise against any movement to give families the predominant voice in determining placement. It would also be unwise to ignore the financial consequences of non-essential use of long term facilities.

C REISNER

Department of Geriatric Medicine,

London Hospital,

1 Hodkinson HM, Hodkinson I. Death and discharge from a geriatric department. Age Ageing 1980;9:220-8.

2 Farrow SC, Rablin MR, Silver CP. Geriatric admissions in east London 1962-72. Age Ageing 1976;5:49-55.

3 Isaacs B. Prognostic factors in elderly patients in a geriatric institution. Gerontologia Clinica 1965;7:215.
What contribution has cardiac surgery made to the decline in mortality from coronary heart disease?

SIR,-As Drs John M Neutze and Harvey D White point out (14 February, p 405), a major problem in assessing the contribution of cardiac surgery to the decline in coronary heart disease mortality is in estimating the potential mortality of the surgical patients had they not had surgery. The earlier, and much lower, estimates are a result of different assessments of the likely benefit of surgery. Drs Goldman and Cook ${ }^{1}$ and $\mathrm{I}^{2}$ prefer an estimate based on a randomised clinical trial, with all its limitations. Drs Neutze and White prefer estimates based on a variety of case series from North America (which I used in estimating an upper limit of benefit). It seems, however, that because of the lack of appropriate data from Auckland on the survival of a comparable group of medically treated patients Drs Neutze and White are guilty of the same "conceptual fallacy" as previous investigators

It might be useful to take a broader look at the potential impact of cardiac surgery. In New Zealand coronary heart disease mortality has declined in all age, sex, and race groups. In general, however, coronary surgery has been restricted to people under 70 years of age. Moreover, the decline in mortality began well before coronary artery bypass surgery was introduced in New Zealand. To suggest that surgery alone was responsible for a major part of the decline (26-42\%) requires a complex explanation of the overall decline as other factors must therefore be operating in the population subgroups not exposed to surgery.

Another explanation would be that the major factors in the decline must be those to which the whole population is exposed. Evidence from New Zealand shows, in fact, that dietary changes and, to a lesser extent, a reduction in tobacco consumption are likely to be the major factors in the decline in coronary heart disease mortality. ${ }^{3}$

University of Auckland,

ROBERT BEAGLEHOLE

New Zealand

1 Goldman L, Cook EF. The decline in ischemic heart disease mortality rates: an analysis of the comparative effects of medical interventions and changes in lifestyle. Ann Intern Med 1984;101:825-36.

2 Beaglehole R. Medical management and the decline in mortality from coronary heart disease. $\mathrm{Br} M e d \mathcal{f}$ 1986;292:33-5.

3 Jackson RT, Beaglehole R. Dietary fat, serum cholesterol, cigarette smoking and the decline in coronary heart disease mortality in New Zealand. Int $\mathcal{J}$ Epidemiol (in press).

\section{Eczema herpeticum: a potentially fatal} disease

SIR,-As Dr I $R$ Sanderson and colleagues (14 March, p 693) rightly point out, eczema herpeticum - and eczema vaccinatum before smallpox vaccination was stopped-is a potentially fatal disease. During 1950-5, 16 cases of eczema herpeticum were seen at the Hospital for Sick Children, Great Ormond Street. ${ }^{1}$ Of these, 11 were considered to be severe, with fever lasting more than 12 days. In September 1953 an outbreak of eczema herpeticum occurred in the skin ward of the hospital. Six severe cases developed, and in one of these the patient died on the tenth day of the illness. ${ }^{2}$ The outbreak probably occurred because of incorrect diagnosis in the first case, ${ }^{23}$ and herpes virus infection was spread by two nurses who had cutaneous vesicular lesions on the hands. All cases of herpes infection were confirmed by virus isolation. In the patient who died diffuse necrotic lesions were found in the adrenals and also in the liver and lungs. ${ }^{2}$ The presence of herpetic type inclusion bodies and isolation of virus from these organs indicated that herpes virus was responsible for these typical and atypical necrotic lesions. In two subsequent fatal cases necrotic lesions were found confined to the adrenals.

One of the patients affected by the ward outbreak subsequently suffered four separate attacks of eczema herpeticum with thrombocytopenia and died at the age of 4 years with diffuse eczema herpeticum, chronic interstitial pneumonitis, and advanced glomerulonephritis, complicated by an overwhelming infection with Pseudomonas pyocyanea. $^{3}$ Some years later, when this case was reviewed, it was realised that this patient was probably suffering from the Wiskott-Aldrich syndrome.

I agree with Dr Sanderson and colleagues that early identification and treatment may be life saving, as is recognition of the mode of spread. Unfortunately, when these cases were seen modern methods of treatment of eczema were not then available.

J A DUDGEON

Ashford,

Kent TN25 7AZ

1 Jackson ADM, Dudgeon JA. Kaposi's varicelliform eruption: diagnosis and treatment. Great Ormond Street foumal 1951;1:125-32.

2 Rugh RCB, Dudgeon JA, Bodian M. Kaposi's varicelliform eruption (eczema herpeticum) with typical and atypical visceral lesions. Foumal of Pathology and Bacteriology 1955;69:67-80.

3 Institute of Child Health. A case of recurrent Kaposi's varicelliform eruption. BrMed $\mathcal{J} 1962$;i:313-20.

\section{Outbreak of Weil's disease in a food fad} commune in India

SIR,-In response to the queries made by Dr Singh (14 February, p 443), we would like to reiterate that in our report the patient in the index case, which alerted us to the fact that rat meat was the source of infection, did not belong to the Mussher commune and did not participate in the catching, handling, or cooking of the rats.

Musshers are basically wandering communes and are considered to be untouchable. A few such communes, however, have undergone sociocultural changes. After independence considerable efforts were made to bring about agricultural reform, and some landowners started to employ members of Mussher communes as agricultural workers and allowed them to settle permanently outside the main village. Nevertheless, they are still at the mercy of the landowners, and because they are considered to be untouchable they have never been allowed to live inside the villages.

One group of the tribe still wanders from one village to another, its members earning their living by performing various plays and tricks.

As we stated in our article, the rats were grilled hastily over a makeshift bonfire, without the use of cooking utensils or the addition of salt during cooking. Salt was smeared on the meat only at the time of consumption, and it is therefore highly unlikely that salt destroyed leptospira, especially at the centre of the rat meat. Dr Singh should also be aware of the fact that in most of rural India the villagers believe that the sprinkling of salt over fire invites a catastrophe like leprosy.

It is true that leptospires usually fail to survive in gastric acid, but they can easily enter abraded skin or mucosa. ${ }^{1}$ In the index case the leptospires in the contaminated food may have entered through the upper gastrointestinal mucosa or escaped destruction by gastric hydrochloric acid.

Though some of the Musshers' habits might 
suggest that they are at high risk of developing leptospirosis, the remarkably low incidence of the disease in such communes argues to the contrary. The clustering of so many cases in the commune, the finding of only a moderate rise in the temperature at the centre of a meatball cooked on a hot plate ${ }^{2}$ and the very peculiar interaction of the index case with the commune strongly suggested that food was the common source.

D K SRIVASTAVA

Patna Medical College Hospital,

Patna 800004

1 Sanford JP. Leptospirosis. In: Petersdorf RG et al, eds. Harrison's principles of internal medicine. New York: McGraw Hill, 1983:1048-51.

2 Pardisi F, Bartoloni A, Aquilini D. Is fast food toxo food? NEng f Med 1985;313:1092.

\section{Immunoscintigraphy of metastases with} radiolabelled human antibodies

SIR,-Dr F Al-Azzawi and coworkers (28 February, $p$ 546) comment that the dose of antibody that they used $(700 \mu \mathrm{g})$ was far below that normally used for immunoscintigraphy with rodent antibodies. We have had considerable experience of monoclonal antibody imaging over the past five years and have successfully identified tumour sites using $200 \mu \mathrm{g}$ of murine monoclonal antibody radiolabelled with $1.5 \mathrm{mCi}$ iodine- $131 .^{12}$

We would like to point out that the physical characteristics and quantity of the radiolabel used have at least as great an influence on image quality as the quantity of antibody used and that the dose of iodine-131 used in the report by $\mathrm{Dr}$ Al-Azzawi and coworkers $(1.5 \mathrm{mCi})$ is similar to that used in most immunoscintigraphy studies. ${ }^{34}$ The use of human monoclonal antibodies may well allow smaller doses of protein to be used for immunoscintigraphy, but the authors' report does not show this.

Furthermore, we believe that the authors have understated the importance of this work. The production of a human antitumour monoclonal antibody may have considerable implications not only for tumour imaging but also for antibody directed tumour treatment.

\section{K C BALLANTYNE}

A C PERKINS M V Рimм

Department of Surgery,

Queen's Medical Centre,

Nottingham NG7 2UH

1 Farrands PA, Perkins AC, Pimm MV, et al. Radioimmunodetection of human colorectal cancers by an anti-tumour detection of human colorectal cancers by
monoclonal antibody. Lancet 1982;ii:397-400.

2 Ballantyne KC, Perkins AC, Pimm MV, et al. Localization of monoclonal antibody-drug conjugate 791T/36-methotrexate in monoclonal antibody-drug conjugate 791
colorectal cancer. Br $\mathcal{J}$ Surg 1986;73:506.

3 Berche C, Mach J-P, Lumbroso J-D, et al. Tomoscintigraphy for detecting gastrointestinal and medullary thyroid cancers; first clinical results using radiolabelled monoclonal antibodies against carcinoembryonic antigen. $\mathrm{Br} M e d$ f 1982;285: 1447-51.

4 Epenetos AA, Britton KE, Mather S, et al. Targeting of iodine123 labelled tumour associated monoclonal antibodies to ovarian, breast and gastrointestinal tumours. Lancet 1982;ii: 999-1004.

\section{Late abortions}

SIR,-After the Bishop of Birmingham's bill and the case of C $v$ S Dr Peter Bromwich's article (28 February, p 527) is well timed. He suggests that the lowering of the limit to 24 weeks would prevent abortions for severe fetal defects, but there is a widely used solution to the problem of late diagnosis of fetal abnormality.

Take the case of babies with Potter's syndrome or anencephaly who are diagnosed by ultrasound examination at 32 weeks' gestation. The mothers are informed that the babies will survive for only a short while after birth. It can be said that such babies are capable of being born alive but are not viable. Many mothers in these unfortunate circumstances express a desire to end the pregnancy, thereby foregoing eight weeks of carrying a doomed baby. It is widespread practice to offer these patients induction of labour to end the agony, especially as such babies are likely to die more quickly with the added burden of prematurity. I have to admit that this is termination of pregnancy but is it abortion or child destruction?

District General Hospital,

VinCENT ARgent

Eastbourne,

East Sussex BN21 2UD

\section{Points}

\section{AIDS and intravenous drug use}

Dr D J GoldBerg (Ruchill Hospital, Glasgow G20 9NB) writes: I wonder if Dr Peter J W Wood's belief that drug misusers "have encountered few if any barriers in obtaining needles and syringes" and that "in many areas of the country needles and syringes may be bought from chemists" (28 February, p 571) are true of the whole country. Because of the number of intravenous drug users in Glasgow (5000-10000) 39 pharmacies throughout Glasgow were studied to determine the availability of needles and syringes. Pharmacies were classified as being in areas with large population of intravenous drug users (A), an intermediate population (B), or a low population (C) When the pharmacists were asked whether they sold needles and syringes, four in group A replied yes and 15 no; none in group $B$ replied yes and 11 no, and six in group $C$ replied yes and three no. Only $16 \%$ of the pharmacies were prepared to sell needles and syringes in areas considered to have large populations of intravenous drug users, and indeed many of these areas had no retail source of needles and syringes whatsoever. Of those prepared to sell, most did so reluctantly, and usually only diabetic syringes (often unacceptable to drug users because of the size of the barrel and needle) were available.

\section{Child abuse}

Dr Geraldine R Boocock (Bury, Lancashire BL0 9RZ) writes: I disagree with Dr Bernard Valman (7 March, p 633) on one point: when a child with a fairly minor injury is examined from top to toe by paediatrician and then admitted to hospital the reason is usually only too clear to the parents. The relationship between the doctor and parents in cases of suspected child abuse is at best a delicate one, and failure to explain the real reason for admission at an early stage can destroy it completely. Diagnosis of abuse is not an end in itself but is usually the starting point of work with the family. This will fail unless a policy of frankness and open discussion is pursued from the start.

\section{Syringe driver in terminal care}

Dr D SNADDEN (Beauly, Inverness-shire IV4 7DT) writes: The rural practice in which I work has recently acquired two Graseby MS 26 syringe drivers, which have revolutionised our ability to provide adequate relief from the symptoms of nausea and pain normally associated with terminal disease and enabled us to keep patients comfortable at home who might otherwise have ended up in hospital. The days of patients experiencing breakthrough pain while waiting for the doctor or district nurse to drive 10 miles to give them a pain relieving injection are now gone. We have found the MS 26 series syringe drivers to be extremely well suited to terminal care in general practice. They are convenient to use, as Dr Simon B Dover pointed out (28 February, p 553), and seem very robust and reliable. Having experimented with various combinations of antiemetics and diamorphine, we have found the most popular mixture to be that of metoclopramide and diamorphine. I would urge all practitioners interested in terminal care to consider acquiring such a machine. This is the sort of venture that communities can easily be persuaded to donate the right sort of funds for.

\section{The elusive orthopaedic senior house officer}

Dr J K Anand (Peterborough Health Authority, Peterborough PEl ILN) writes: With reference to the shortage of orthopaedic senior house officers (14 March, p 70), in the short term we ought to tap the sizable European Community reservoir, particularly as doctors from European Community countries are acceptable here and experience few registration problems. In Peterborough Health Authority we have recruited doctors from Holland, as have other health authorities. Similarly, in long term planning we should consider the medical manpower needs of the European Community as a whole, bearing in mind the fact that a fully trained doctor has a professional lifespan of 30 years or more. We should be prepared to reduce and expand the intakes of medical schools throughout the European Community from time to time in order to balance demand and supply.

\section{Poor start for the Health Education Authority}

Dr C F Donovan (Temple Fortune Health Centre, London NW11 7TE) writes: At a time when, like Dr Richard Smith (14 March, p 664), many in the profession are taking a more realistic view of prevention and health promotion should we not be asking what has happened to the old Health Education Council and why? Unless those who believe in a health rather than a sickness service raise their voices to express their anxiety it could be that the old council will quietly be taken over by people more interested in propaganda and politics than the highly professional activity of health education, and much of the skill developed over the years could be lost. The Health Education Council had a primary care advisory working party, which evolved from the old general practitioner working party that I chaired for several years. It is to be hoped that the new authority will continue some system whereby those who work in primary care may not only advise but also help to plan campaigns such as those on heroin abuse and the acquired immune deficiency syndrome. Experience of such campaigns shows that there is a danger not only of poor evaluation but also of failure to realise that it is necessary to inform and help those working at the "coal face" at the same time as putting out national messages. I hope that the new health authority will realise these needs, but why the long silence? Why not more consultation in the setting up of the authority? Dr Smith has shown us the way. Those of us who feel anxieties should voice them now before it is too late.

\section{Corrections}

\section{Osteoporosis: cause and management}

We regret that an error occurred in this letter by $\mathrm{Mr} \mathrm{A}$ W Fowler (14 March, p 701). The end of the first sentence in the second paragraph should have read: "that osteoporosis related to age is an atrophy of bone caused by disuse" (not "disease").

\section{Why doctors must grapple with health economics}

We regret that a printing error occurred in this letter by Dr R A Storring (21 March, p 769). The second sentence should have read: "Mr Appleby ... seems to be unaware of the role of the clinician" (not "children"). 